\title{
How (not) to think of the 'dead-donor' rule
}

\section{Adam Omelianchuk}

\begin{abstract}
Although much has been written on the dead-donor rule (DDR) in the last twenty-five years, scant attention has been paid to how it should be formulated, what its rationale is, and why it was accepted. The DDR can be formulated either in terms of a Don't Kill rule or a Death Requirement, the former being historically rooted in absolutist ethics and the latter in a prudential policy aimed at securing trust in the transplant enterprise. I contend that the moral core of the rule is the Don't Kill rule, not the Death Requirement. This, I show, is how the DDR was understood by the transplanters of the $1960 \mathrm{~s}$, who sought to conform their practices with ethics, unlike today's critics of the DDR who "rethink" ethics in a question-begging fashion to accommodate their practices. A better discussion of the ethics of killing is needed to move the debate forward.
\end{abstract}

\section{Introduction}

In the past twenty-five years, much work has been published on the so-called "dead-donor" rule (DDR) and the alleged problems it poses for organ transplantation. Most of this literature is critical of the rule and calls for its abandonment, yet the rule's exact formulation is not always clear and the reasons for abandoning it are not always sound. Indeed, as I argue in the first section of this paper, there are two distinct ways of formulating the rule, both of which lend themselves to distinct ways of justifying their application. On the one hand, the DDR is interpreted as a requirement that the donor be dead before surgery begins, a rule that appears to form a prudential policy essential for securing the trust of potential donors in the transplant enterprise. On the other hand, it is interpreted as a norm against intentionally killing the innocent via transplant surgery, a norm that is historically rooted in the absolutist ethical systems of Kantian deontology, natural law theory, and religious ideas embedded in Judaism and 
Christianity — not in principles of utility. ${ }^{1}$ Hence, it is insufficient to argue from the premise that the DDR has negative effects on donor trust (assuming this is the case) to the conclusion that it should be rejected (e.g. [2]), since the validity of the norm against killing individuals for their organs need not depend on whether the killing produces good consequences. As a deontological constraint, the DDR forbids lethal transplant surgery as a type of action - and this, as I defend in the second section, is the moral core of the DDR. While the theoretical limits of this constraint are hotly debated today, it was originally received as an absolute ban on lethal surgery. As shown in the third section, the early transplanters of the 1950s and '60s had good reasons for understanding the rule this way, and they labored to make their practices conform with the law and long-standing ethical principles concerning the ethics of killing. Today, however, we see something of a reversal of this pattern of thought; critics are eager to "rethink" the ethics of killing and laws against homicide to permit lethal practices they assume to be acceptable. In the fourth section, I take issue with this assumption because the question is begged against the traditional reasons that the DDR was adopted for in the first place. Since our medical practices should conform with sound ethical principles no matter how much we may desire for them to be acceptable, I end by calling for the continuation of a more thorough and consistent discussion of the reasons why we should reject the norm against killing the innocent in general and why it should be permissible for doctors to kill for organs in particular. While this may be well-worn territory, it is "the only game in town" for moving the debate forward. Let us now examine this case in greater detail.

\footnotetext{
${ }^{1}$ Lest there be any confusion, the kind of "absolutism" I have in mind is the kind G.E.M. Anscombe described when she spoke of there being "certain things forbidden whatever consequences threaten" and "simply in virtue of their description as such-and-such identifiable kinds of action...” [1, p. 10] (emphasis original).
} 


\section{What does the rule prohibit?}

Careful thinking about the DDR requires a clear formulation of its content. Surprisingly, this step is often glossed over. A sample of the literature reveals two different ways in which the DDR is formulated, one I call the "Death Requirement" and the other I call the "Don't Kill" rule:

\section{Death Requirement}

1. "It is thought permissible to retrieve vital organs only from dead patients." [3]

2. "A patient should be dead before vital organs were removed." [4, $\mathrm{p}$. 249]

3. "The donor must be dead before vital organs are procured." [5, p. 670]

4. "Multiple vital organs should only be taken from dead patients." [6, p. 236]

\section{Don't Kill}

1. "It is immoral to kill patients by taking their organs." [7, p. 1]

2. The DDR "requires that donors not be killed in order to obtain their organs." $[8, \mathrm{p} .6]$

3. "Individuals must not be killed by organ retrieval." [9, p. 36]

4. "The DDR states that organ donation must not kill the donor; thus, the donor must first be declared dead." [10, p. 1289]

As stated, the Don't Kill rule is less demanding than the Death Requirement because it permits vital organ procurement in cases where surgery is causally unrelated to death, where the Death Requirement does not. While commonsense suggests that removing a vital organ like the heart would cause the death of the donor, this is not necessarily the case in practice. Astonishingly, the heart can be removed without killing the donor in what is called a "domino donation." In this protocol, a donor with a healthy heart but diseased lungs can donate her heart to someone else, and receive a healthy heart and lungs en bloc from a dead donor. ${ }^{2}$ To be sure, those who deploy the Death Requirement in their writings would probably deem this practice as acceptable and admit that the Death Requirement, as stated, is imprecise. ${ }^{3}$ Critics of the rule have a point, then,

\footnotetext{
${ }^{2}$ Robert Sade, e-mail message to author, October 26, 2015.

${ }^{3}$ Or, as an anonymous reviewer suggests, they might even consider the particular organs harvested in this specialized context as technically "non-vital."
} 
when they say that the ethically relevant question is not "When is the donor dead?" but rather "When is it permissible to remove vital organs from the donor?" [4]. However, death is still an important part of answering this question if the donor's death is not to be intended [11].

The Don't Kill rule, by contrast, says that it is impermissible to remove vital organs from the donor if the donor would be killed by their removal, since the donor's death should not be intended for the sake of retrieving organs. ${ }^{4}$ Some critics and defenders of the rule agree that this is its morally relevant formulation, being a species of the more general norm against harming patients. ${ }^{5}$ Critics of the rule, like Franklin Miller and Robert Truog, recognize that "it is based on the seemingly unassailable principle that it is wrong to kill (or cause the death) of an innocent person to save the life of another" [3, p. 38]. Moreover, as George Khushf, a defender of the rule, explains, the rule "excludes organ-harvesting practices that bring about mortality" [12, p. 256, n. 1], or put another way, "no person can be killed in order to harvest organs" [12, p. 331]. Therefore, the ill-named 'dead-donor rule' should be interpreted primarily as a reference to the norm against killing donors for their organs, and not primarily as a proscription against the removal of vital organs from living patients, as commonsensical as that might be. ${ }^{6}$

What, then, explains the prominence of the Death Requirement? Although the Don't Kill rule is the essential moral core of the DDR, one might think that the Death Requirment is the

\footnotetext{
${ }^{4}$ One should not interpret the DDR so narrowly as to think that it only forbids killing by removing organs, but not killing for obtaining organs (pace Christian Coons and Noah Levin [6]). The fact that one could consent to be killed by the surgical removal of organs but not for the sake of their removal is simply irrelevant in the context of organ donation, the context to which the DDR applies (such a person is not a "donor" at all). In that context, no donor is indifferent to the good of having one's organs harvested for the sake of helping others, and no transplant team is indifferent to the good of harvesting healthy organs for transplant.

${ }^{5}$ This would also rule out procurement procedures that would leave individuals in a diminished state, even if they were not killed.

${ }^{6}$ Levin is one of the few writers on this topic who notes the difference between the Death Requirement and the Don't Kill rule, but he thinks that the Death Requirement is the "historically accurate" formulation despite conceding that "the origins of the DDR are unclear" [13, p. 2-3]. Both of these claims I contest below.
} 
best policy to adopt to avoid risking abuse and to secure donor trust. Obviously, transplant surgery is less controversial when the donor is dead. Technically, however, the Don't Kill rule allows vital organs to be procured so long as the donor is not killed by the procedure, and these surgeries are much more controversial. For example, under Paul Morrissey’s proposal, a surgeon may remove both kidneys from someone who is irreversibly brain-damaged but does not satisfy neurological criteria for death [14]. Under this protocol, a designated proxy authorizes the removal of the kidneys before life support is removed; once the kidneys are retrieved, life support is withdrawn, and the donor dies of respiratory complications. Assuming the cause of death is related to the fatal brain trauma and not to the absence of kidney functioning, the Don't Kill rule is not violated. ${ }^{7}$ Crucial to this proposal are the certainty of the diagnosis of imminent death and the substantial cause of death. ${ }^{8}$ This is a demanding standard, and any errors in diagnoses would be catastrophic for the patient, while implicating the surgeon in the donor's death. Even if the diagnosis is correct, doctors must still consider the risk of the surgery's being the proximate cause of death. ${ }^{9}$ To avoid any risk of violating the Don't Kill rule, then, the best

\footnotetext{
${ }^{7}$ Some contend that the Don't Kill rule is violated because withdrawing life support is what "causes death" not the underlying pathology $[15$, p. 2]. While this requires fuller treatment, my quick reply is that framing human action in terms of its causal activity or inactivity is a poor way to understand human action. Does a boy scout "cause the death" of his breathless and unconscious scout master (imagine some accident out on the trail) when he ceases to perform mouth-to-mouth resuscitation after an hour? The fact that the scout master could have lived longer had the scout not given up is not sufficient for helping us understand what the scout does-certainly he does not kill him. It seems that there is at least a morally relevant distinction between being $a$ cause of death (which may affect the timing of it) and being the cause of death (which is the source of the fatal sequence) [16]. This is not to say that someone's death cannot be intended by withdrawing life support, but doing so does not require such an intention. For further treatment on this topic see Jensen [17].

${ }^{8}$ This is also the source of the controversy over so-called "donation-after-circulatory-death" protocols.

${ }^{9}$ According to critics of Paul Morrisey's proposal:

Midline laparotomy and bilateral nephrectomy [the procedures that remove both kidneys] after the original brain injury is an additional iatrogenic (penetrating and blunt) trauma resulting in extracranial tissue injuries and potentially hastening or causing death. Surgery can induce post-operative cardiovascular instability secondary to blood loss, intraoperative fluid shifts, and intravascular hypovolemia. In the absence of optimal perioperative resuscitation, the final common pathway is an early onset of hypotension and cardiovascular collapse. The latter becomes the lethal pathophysiology and proximate cause of death upon WLS [withdrawing life support]. [18, p. 18]
} 
policy is to satisfy the Death Requirement, a standard Morrissey's proposal does not meet. Thus, a precautionary approach that avoids contravening the Don't Kill rule gives the Death Requirement its normativity. The normativity of the Death Requirement may also be reinforced with the belief that it best protects the patient's end-of-life care from being compromised and, therefore, better secures donor trust in the transplant system. For these reasons, the stronger Death Requirement might be preferable to the weaker Don't Kill rule, which would help explain its prominence. ${ }^{10}$ Yet if the risk of violating the Don't Kill rule were shown to be tolerable, and the patient's end-of-life care were able to be safeguarded, Morrissey's proposal would be permissible insofar as the Don't Kill rule is concerned. What is at stake is the suitability of certain protocols that do not meet the more risk averse Death Requirement: are they safe enough to practice, or would we risk killing the donor? How Morrissey's proposal is adjudicated will depend not only on the answer to this question but also on the interpretation of the rule favored as a matter of policy. What is important to understand for our purposes is that the moral core of the DDR is the Don't Kill rule, and the Death Requirement is the operational result of a precautionary approach to complying with it. This type of framing has important implications for understanding the DDR's purpose.

\section{What is the rule's purpose?}

The DDR is commonly recognized to be a deontological constraint on our efforts to maximize the number of transplantable organs, but the meaning of this notion is unclear. In a broad sense,

\footnotetext{
${ }^{10}$ This sort of thinking is captured well in DeVita and Snyder's description of four cases in which donation-aftercirculatory-death protocols were used [19]. They report that, in the effort to standardize these protocols, some transplant teams and procurement officials were concerned "that an overly liberal policy might result in a public outcry that would jeopardize the future of organ donation" [19, p. 136]. I take what they mean by an "overly liberal policy" to include removing vital organs from donors who have satisfied neither neurological nor circulatory criteria.
} 
it means that, regardless of the consequences, we must not instrumentalize donors to such an extent that they can be killed for their organs. Yet the limits of this constraint are up for debate. Can donors be killed for their organs if they give valid consent? Or would such cases be ruled out because they involve killing the innocent? ${ }^{11}$ The answer depends on which form of deontology is at work. If the broadly Rossian variety found in Tom Beauchamp and James Childress' widely read Principles of Biomedical Ethics is at work [20], then exceptions to the Don't Kill rule can be plausibly formulated through the mechanism of voluntary informed consent. However, if the absolutist variety deriving from Kant's ethical system, natural law theory, or Judeo-Christian morality is at work, then no exceptions can be made - the Don't Kill rule is simply meant to forbid this type of action. Rather than settle this philosophical debate here, I will just say that the historical understanding of the DDR in the 1960s favored the absolutist sort (see below for details). The particular reasons for this leaning depend on the tradition assumed, but a respect for the inviolateness of innocent human life is the underlying concern. Interestingly, some critics of the ban recognize that its character signifies society's respect for human life [21], while some of its defenders pass over this issue entirely and emphasize its utility, claiming that compliance is essential for securing the trust of willing would-be donors [22]. It is thought that donor trust would be curtailed if the rule were routinely violated [10]. These two trains of thought are often blended together in ways that make the purposes of the rule reducible to respecting persons and avoiding harm (e.g. [22]). As today's bioethicists tend to work out their policies in terms of a quasi-rule utilitarianism where principles

\footnotetext{
11 There is a question about the "non-innocent" - people on death row-which I leave aside, since such a practice depends on the validity of the death penalty, an issue that needs to be resolved before any "death-by-transplantsurgery" proposal can be evaluated.
} 
of respect are "balanced off" with principles of beneficence (e.g. [23]), ${ }^{12}$ the purpose of the DDR is thought to be twofold: (1) to protect the interests of the donor, and (2) to secure the goods necessary to further the goals of transplantation. This more pragmatic interpretation of the rule explains why some people think the DDR "never really has been a rule, but rather a guideline" [4, p. 252]. This, however, is an impoverished view of the rule's purpose. To see why, I shall examine two flawed criticisms of the rule, which depend on these assumptions.

\section{Not about successful mediation}

Critics of the DDR typically contend that the rule should be rejected if it is at odds with the respect for persons or if it fails to secure the trust it promises $[2,7,9,25,26]$. This is an instance of a more general strategy, which argues against the rationality of accepting an absolute prohibition from the premise that perfect compliance with it frustrates the purposes of the prohibition [27]. Perhaps the best example of this critical framework comes from Elysa Koppelman, who thinks the DDR ought to be discarded because it can no longer "successfully mediate" the utilitarian goal of maximizing the organ supply with the deontological value of respecting the wishes of donors who are irreversibly unconscious [7, p. 2]. Successful mediation of these goals is what she believes characterizes the concerns of the transplant community. While she formulates the DDR in terms of the Don't Kill rule, she believes that compliance requires a precise definition of death when the surgery for successful transplant would otherwise kill the donor. Since there is a lack of consensus on the definition of death, she concludes that the DDR cannot "mediate the concerns of the organ transplant community," and if we assume that

\footnotetext{
${ }^{12}$ Albert Jonsen is worth quoting: "To be more precise [...], the 'rule utilitarianism' that combines respect for rule and principle with the the goals of human and social thriving is the dominant ethos of bioethics at the level of public policy"[23, p. 44].
} 
respecting persons and killing them are incompatible, "we risk compromising the utilitarian goal" $[5$, p. 5]. To achieve a more optimal balance between the utility of maximizing the organ supply and the deontological value of respecting those who supply them, we ought to permit donors to negotiate their deaths with their transplant surgeons.

There are two problems with this argument. First, it is doubtful that the purpose of the DDR is to "successfully mediate" the delicate balance between the good of maximizing the organ supply and the good of respecting the organ suppliers. Instead, the DDR is meant to conflict with the utilitarian goal - it is not meant to identify a neutral space of moral ground where the principles of beneficence and respect for persons can meet. ${ }^{14}$ The rule is merely meant to forbid a certain kind of action from being performed on the donor's body. Second, there is no good reason why a lack of consensus on a topic is sufficient to reject rules that involve the topic. Koppelman's argument seems to be this:

1. The DDR requires a precise definition of death.

2. There is no consensus on the definition of death.

3. Therefore, the DDR ought to be rejected.

I shall call this the No Consensus argument. Its general form goes like this:

1. Rule $\mathrm{R}$ concerning $\mathrm{Q}$ requires that there be a precise definition of $\mathrm{Q}$.

2. There is no consensus concerning the precise definition of Q.

3. Therefore, $\mathrm{R}$ should be rejected.

Is her application of this argument sound? I think not. Consider this argument:

1. Rules that protect the free exercise of religion require a precise definition of "religion."

2. There is no consensus on the definition of "religion."

3. Therefore, rules that protect the free exercise of religion ought to be rejected.

\footnotetext{
${ }^{14}$ I take her language about "utilitarian" and "deontological" values to be indicative of a conflict between the standard bioethical principles of beneficence and respect for persons, not utilitarian or deontological ethics in a theoretical sense.
} 
Yet we have good reason to accept rules that protect the freedom of religion despite the fact that there is no consensus on the definition of religion [28]. Some of those reasons involve the principles of beneficence and respect for persons, or other principles upon which any just society is based [29]. The same is true of rules protecting ideals like free speech or the freedom to marry, or rules making use of disputed concepts like race or gender. Yet the No Consensus argument would have us believe that any term's lack of consensus definition is grounds for rejecting rules that make use of this term. There is simply no reason to accept this view. One might reasonably conclude the rules are problematic or in need of refinement, but the implication that they should be rejected does not follow.

I will grant that perhaps I am missing something important about when and why a rule's terms need to be clearly defined. Nonetheless, it is not obvious that the DDR requires a precise definition of death. Under the Don't Kill formulation at least, one is in need of a good understanding of life and the knowledge of how not to take it—not a precise definition of death. But what about the Death Requirement? Is is not the case that a precise definition of death is necessary to determine when we can safely remove vital organs? Surprisingly, the answer is no; a precise definition of death is not needed when individuals donate their brains to science. No one worries about satisfying rigid death criteria when the brains of former football players are removed upon autopsy so that they can be studied for the purpose of diagnosing chronic traumatic encephalopathy (popularly known as CTE). Rather, the requirement is generated by procedures that intend to retrieve the healthiest organs possible for transplant and that accept the DDR as a constraint. Thus, it is the medical goals of organ transplantation in conjunction with the constraint of the Don't Kill rule that require a precise definition of death. Yet many critics of the rule believe that either version of the DDR alone imposes this requirement. This is an 
instance of a broader trend in the DDR literature, which I call "slanting" (for lack of a better term): attributing things we do not like to a single factor, while ignoring the relevance of other factors.

Not about creating virtuous activity or good consequences

A notable example of slanting comes from Frank Chaten [2], who asserts that the DDR has failed to perform its intended function, that is, to safeguard patient trust in the transplant enterprise. According to Chaten, compliance with the DDR "leads physicians to compromise many virtues essential to the excellent practice of medicine" [2, p. 496]. Abolishing the rule will remedy this situation, says Chaten, because it "will strengthen the doctor-patient relationship and foster trustworthiness in organ procurement" [2, p. 496]. Chaten's critique is interesting in that it is not merely consequentialist; rather, he assumes the virtue ethics tradition as it is situated in medicine by Edmund Pellegrino [30]. The virtues at stake include: (a) fidelity to the patient's best interests with respect to the desire to donate; (b) intellectual honesty with respect to the nature of death; (c) suppression of self-interest and the courage to support the good with respect to the difficulty of diagnosing death while simultaneously promoting the urgency of altruistic gifting; and lastly (d) compassionate care for the donor with respect to failure to administer general anesthesia to newly declared dead donors for precautionary reasons. Chaten's consequentialist concern is that the application of the DDR at the bedside fails to bring about desirable states of affairs, that is, ones in which physicians accord with virtuous activity. Since transplant surgeons do not accord with these virtues, says Chaten, their activity undermines trust in the transplant system. To safeguard trust, then, we ought to reject the DDR.

Supposing for a moment that the primary purpose of the DDR is to safeguard trust (which it is not), Chaten's argument fails to isolate the DDR from other relevant factors in cases where 
the rule is applied so that the DDR can be properly blamed for undermining trust. For example, he believes the DDR disrespects donors by limiting their ability to donate healthy organs in cases where the donor does not die quickly enough. However, this problem arises only in donationafter-circulatory-death (DCD) cases, not in brain death cases where the donor's body is artificially ventilated. As for brain death cases, Chaten believes that the DDR sometimes forces physicians to impose brain death on donors and their families who for religious reasons may not agree that brain death is death. He cites an example in which he cared for a Muslim child whose parents rejected brain death, believing that death occurs when respiration expires. What goes unmentioned, however, is that these same parents would probably not allow their child to be killed on the operating table either. Hence, it is the medical and legal establishments' commitment to brain death that creates a burden for cultural and religious values, not the DDR. As unfortunate as it may be when DCD donors fail to die quickly enough to donate healthy organs, it does not follow that the donor's autonomy is disrespected if the acting transplant surgeon refuses to perform lethal surgery. Doctors are autonomous agents too, and by virtue of the respect they are due, they reserve the right to not intend the death of their patients - even in a world without the DDR. Then, perhaps it is worth examining whether our protocols fail to exemplify virtuous activity; maybe they, and not the DDR, are to blame for undermining trust in the transplant system.

Chaten might reply that protocols like those currently used for DCD are the "offspring" of the DDR [2, p. 497]. If by this he means that such protocols are the product of a marriage between transplant medicine and the DDR, then so be it - this position is compatible with my claim that the DCD protocols in question may or may not be consistent with virtuous activity. In fact, there is some evidence to suggest that the transplant surgeons of the early 1960s were 
uncomfortable with harvesting organs after circulatory death. Thomas Starzl remarked that the complicated maneuvering required to procure a healthy kidney after circulatory death led him and his colleagues to fear that they were violating the "spirit" of the "law"- that is, the law against homicide - even if they were following the "letter" of it [30, p. 149]. Should this discomfort not count as evidence that the DDR had a virtuous effect on early transplanters? After all, the rule's spirit, if not its letter, revealed something important about the character of their actions, which led them to rethink their practices in order that they be able to treat the donor with greater respect. Chaten probably would not agree, however, because he sees the commitment of early transplant teams to the DDR as an "unexamined choice, not conceived by thoughtful analysis of alternatives or the result of wisdom obtained from the bedside" [2, p. 498]. As such, he claims that the rule was put forward merely as a pragmatic solution to the problems facing transplant surgery in the 1960s, and the pioneers of the discipline did not understand that they were creating the conditions for an imprudent medical practice. Is this true? I think not, and, as I argue in the next section, the acceptance of the DDR was the result of complying with not only the law against homicide but also traditional norms against killing patients for any reason, which were stringently reapplied after World War II. This context explains, in part, why Starzl and his colleagues thought they were not complying with the "spirit" of the law in the days before the legal recognition of brain death as death.

\section{Why did the early transplanters accept the DDR?}

Since the goal of organ transplantation is to replace an unhealthy organ with a healthy one, the body from which the healthy organ is taken must be in good enough shape to supply one. Assuming vital organ removal would bring about mortality, a dilemma emerges. Either we identify some condition of the donor, which is compatible with the donor's being dead and 
allows for the relevant organs to be healthy enough for transplant, and we remove organs only when that condition is reached, or we identify a level of health remaining in the donor, at which point lethal surgery is judged permissible, and we remove organs only when that level is reached. The dilemma pressures us either to precisely define death and reliably determine when it occurs or to revise our ethics of killing and precisely define the conditions under which a patient can be killed. In any case, something must be precisely defined if transplantation is to occur.

When confronted with this dilemma in the 1960s, transplanters opted to "update" the definition of death to include neurological criteria alongside traditional cardiopulmonary criteria $[32] .{ }^{15}$ This move is explained in part by the cultural upheavals of the time, which led some to advocate for the legalization of abortion and euthanasia [33, 34]. What kept the broader transplant community from becoming swept up into a more expansive view of physicianpermitted killing? At least some members were open to this development. Belding H. Scribner, a key innovator in dialysis treatment, said in his presidential address to the American Society of Artificial Internal Organs:

As far as death is concerned, I would like to be able to put into my will a paragraph urging that when my physician felt that the end was near, I be put to sleep and any useful organs taken prior to death. I wonder how many people feel as I do? I think that ethical and legal guidelines should be devised to permit me and others to volunteer in these ways. [35, p. 211]

I too wonder how many felt the same way as Scribner. As far as I know, the attitudes of early transplanters towards this question have not been empirically studied. Still, it should be asked: why did the transplant community lobby for a change in the definition of death rather than in

\footnotetext{
${ }^{15}$ Paul Ramsey's survey of how this "updating" process went about presents the best summary of the relevant issues and events under consideration at the time [32].
} 
homicide law? This question has three answers, each of which is explored in the next three subsections, respectively.

\section{The concern over human experimentation}

The first answer is found in the experimental nature of organ transplantation at the time. The startling long-term success of Joseph Murray and others in kidney transplantation highlighted the newfound awkward relationship between such practices and existing medical, legal, and theological norms $[36,37]$. It was not clear to anyone at the time how the risks involved for both donor and recipient could be justified. Hence, the topic of human experimentation was front and center at the first symposium on transplant ethics held in London at the Ciba Foundation house (March 8-11, 1966). Starzl, who was invited to participate, reported that:

The appropriate conditions for human experimentation was the foremost concern because the medical atrocities of World War II were still fresh in the collective mind. Three of the European participants (David Daube, Regius Professor of Law, Oxford; Hugh Edward de Wardener, nephrologist at Charing Cross Hospital; and Michael Woodruff, professor of surgery, Edinburgh) had experienced violations of their own human rights almost beyond description during years spent in concentration or prisoner-of-war camps. [31, p. 146]

The Nuremburg Code (1947) and the Helsinki Declaration (1964), both of which were index documents for the symposium, call for the uncompromised protection of the life and health of research subjects. Experiments involving a high risk of death or disabling injury to the subject are unacceptable according to these documents, even if the subject gives voluntary informed consent. This protection applied as much to the recipients as to the donors in the early days of transplantation. Murray, who performed the first successful kidney transplant between identical twins in 1954, saw with clarity that the practice of live kidney donation involved risking the

\footnotetext{
${ }^{16}$ In fact, Daube, who fled Germany in 1933, did not spend time in a camp, though his father did [38]. Woodruff and de Wardener spent time in the notorious Changi camp in Singapore.
} 
health of a well person so that a sick person might be made well again [39]. Poor outcomes for the first few liver recipients in 1963 led Starzl and his team to impose a moratorium on the practice for more than three years [31, p. 105].

Starzl's ethical sensitivity is worth examining in detail. In a 1967 article [40], he claimed that the dominant tradition of medical ethics required physicians to provide their patients with the best care possible, no matter the circumstances. As he saw it, this viewpoint "placed the concept of the sanctity of human life on a practical foundation" and should not be abandoned "in the face of advancing technocracy" [40, p. 33]. At the Ciba symposium, he even questioned the practice of removing organs before the cessation of circulation on the basis of neurological criteria and contended that the surgeon and attending physician equally shared the responsibility to protect the lives of potential donors in hopelessly terminal states [41]. ${ }^{17}$ At the time, he felt that the act of removing a kidney from the body of someone declared dead by neurological criteria constituted "an erosion of the historic medical creed of responsibility to the individual patient" [40, p. 36]. He even became uncomfortable with live donation as reports came in about donor manipulation and coercion, and in one case a donor's death [31]. Although his views would change over time to accommodate what is now commonly practiced in transplantation, this transition was not without careful ethical reflection on whether or not longstanding principles of medical ethics were being honored.

Beyond Starzl, participants at the Ciba symposium took the deontic constraints on lethal medical experimentation as given. When Michael Woodruff claimed that there were "obvious limitations" on living donors as organ suppliers, the reason he gave was this: "no one can donate

\footnotetext{
${ }^{17}$ Guy Alexandre's neurological criteria for death, which he used in nine separate occasions, included “(1) complete bilateral mydriasis; (2) complete absence of reflexes, both nature and in response to profound pain; (3) complete absence of spontaneous respiration, five minutes after mechanical respiration has been stopped; (4) falling blood pressure necessitating increasing amounts of vasopressive drugs [...]; (5) a flat EEG" (quoted in [41, p. 69]).
} 
his heart or liver and remain alive, and the same is true of a person who wants to donate a kidney

if he happens to have only one which is functioning" [42, p. 10]. Looking ahead to heart

transplants, George Schreiner curiously said,

I personally would find considerable ethical objections to transplanting a heart, because no matter how certain the doctor is that he has to remove the recipient's heart, he has in effect to kill the patient in order to do the experiment, whereas if he puts the heart in as an accessory organ at least he avoids this problem. [43, p. 132] $]^{18}$

Even the Parisian physician Jean Hamburger, who thought medical practice should be given wide latitude in shaping ethical norms, was committed to a Kantian framework in which "an awareness of the value of human life" was essential to the training of virtuous doctors [44, p. 138]. Echoing this sentiment, the Italian surgeon Raffaello Cortesini claimed unequivocally that "the right to life of every individual must be respected up to the moment of death," when laying out his ideas for proposed legislation in Italy regarding organ donation [45, p. 174]. On the matter of refusing to use children in transplant experiments, Daube was insistent: if by doing so, medical progress would be hampered, then "it is regrettable, but medical progress must then be hampered" [46, p. 199].

The early transplant community accepted the norm against risky experimental surgery, and its members were concerned to make their newly devised protocols as safe as possible for both the donor and the recipient. The American Medical Association echoed this concern in its ethical guidelines for organ transplantation by including a clause calling for equal protection of both donor and recipient; in the Judicial Council's view, no less than the "respect for the dignity of man" was at stake [47]. While the success of these efforts can be debated, the guidelines do offer an answer as to why transplanters did not advocate for a change in homicide law:

\footnotetext{
${ }^{18}$ It seems that Schreiner was committed to the odd view that life is essentially bound up with the presence of a beating heart rather than the presence of adequate circulation.
} 
effectively killing donors for their organs involved lethal, and therefore forbidden, experimental surgery.

\section{The concern over homicide}

The second reason the transplant community advocated for a change in the definition of death rather than homicide law is that doctors did not see themselves as responsible for the deaths of the brain-damaged patients they disconnected from life support. The diagnosis of death became especially pertinent in circumstances involving homicide. The case of David Potter illustrates the problem well. In 1963, Potter suffered extensive brain trauma from a brawl and stopped breathing fourteen hours after being admitted to the hospital. He was subsequently connected to a ventilator so that one of his kidneys could be harvested for transplant. Twenty-four hours later, the kidney was removed and he was taken off life support; no spontaneous breathing resumed. The assailant who injured Potter was arrested and convicted of manslaughter by a jury, but his charges were later reduced to common assault, effectively absolving him of responsibility for Potter's death [32]. The problem was that no one could agree on the moment when Potter died. The coroner thought that he was alive when the kidney was removed, the evidence being his spontaneous heartbeat. The physicians argued that the patient was "virtually dead" when he stopped breathing but "legally dead" when his heart stopped [32, p. 71]. A neurologist contended that Potter was dead before the kidney was removed due to the brain injury; a pathologist concurred and claimed that the removal of the kidney played no causal role in the patient's death [48]. As a result, it was not clear who was responsible for Potter's death. Was it the assailant or the physicians? While it may seem obvious to us today that responsibility lies with the assailant, the law of the day identified the presence of life with a beating heart. Under this view, it is less obvious that Potter's death was caused by the actions of the assailant than by the actions of the 
doctors. Indeed, a legal commenter at the time suggested that the termination of life support was

the "immediate cause" of death, going on to generalize that "if S causes P's death, a strong

argument can be put up for saying that $\mathrm{D}$, the original imposer of the wound, did not, and is not guilty of homicide" $[49$, p. 78$] .{ }^{19}$ How this argument is supposed to go is not clear, but the point is that members of the medical profession — people who were trying to save Potter's lifebecame implicated in his death in ways that made little legal sense. ${ }^{20}$

The Don't Kill version of the DDR, then, was put in place because homicide law made physicians liable for the deaths of patients still alive at the time of transplant [50, 56-58].

Recognizing this, a legal scholar at the Ciba symposium counseled the following:

In the present state of the law perhaps the only thing that one can be dogmatic about is that if life still continues in the conventional sense-e.g. if there is still a heart beat - then certainly any authorization [for transplant] from relatives is meaningless. The living person, however unconscious and unable to express his own opinion, has to be treated as a living person, and any authority from a relative would be meaningless. The problem therefore becomes one of defining the time of death for purposes of these removals. In the present state of the law I could only advise a client that he would incur the danger of a

\footnotetext{
${ }^{19}$ Miller and Truog, who ardently believe physicians cause the death of their patients when they remove life support from them [15], are, in a sense, modern-day witnesses for the defense in the trial of Potter's assailant.

${ }^{20}$ Potter's case was not unique. In May of 1968, Denton Cooley, a pioneering heart transplant surgeon from Texas, came under scrutiny after procuring a heart from a thirty-six-year-old welder named Clarence Nicks, who also suffered severe brain trauma from a brawl. The Harris County medical examiner worried that his autopsy investigation would be compromised if he were tasked with determining the cause of death in someone who no longer had a heart. While he eventually ruled that the cause of Nicks' death was the massive brain injury, the legal definition of death was thought to be in conflict with the changing medical definition, providing the legal space for the defense to assert that it was Cooley, and not the brawlers, who were responsible for Nicks' death [50, 51]. The conflict between medical examiners and transplanters came to a fever pitch when Stanford University's Norman Shumway, another pioneering transplant surgeon, retrieved a heart from the body of a homicide victim without the examiner's authorization. In this case, the defense attorneys succeeded in arguing that it was Shumway who killed the victim, rather than the victim's assailant [52]. Similarly, in 1987, the assailant who shot Pamela James in the head had his murder charges dropped, since his defense attorney discovered in the coroner's report that the time of James' death coincided with the time that the transplant team removed her heart. To bolster his case, the defense attorney enlisted the aid of a neuropathologist, who determined James' brain injury was of a "lower-grade" and did not preclude a chance at recovery. Since James was denied the chance of recovering, his client was not responsible for her death $[53,54]$. In none of these cases was it ever suggested that homicide law should be changed to accommodate lethal surgery, since homicide law was relatively clear, while the definition of death was not. For better or for worse, two concepts of death were emerging, which had far-reaching implications for medical liability and organ transplantation: medical death, based on neurological or circulatory criteria, and legal death, based only on circulatory criteria. Doctors and lawyers struggled to articulate a unified definition of death that would adequately represent the physical facts, while serving the purposes of medicine and law [the best example comes from 55].
} 
possible charge of homicide if by removal of an organ he causes death, if life still continues in the conventional sense. (David Louisell, quoted in [41, p. 98]).

Over time, the legal community came to accept brain death as death. It may very well be that defining death in terms of neurological criteria was merely a pragmatic solution to the legal problems faced by the transplant community. Enthusiasm for this solution was evident at both the Ciba meeting and the Cape Town Symposium (July 13-16, 1968), where protocols for heart transplants were discussed. Yet it is implausible that the DDR was part of this solution; if anything, the rule was part of the problem that needed solving, namely, how surgeons could avoid becoming implicated in the donor's death.

It is important to acknowledge that individuals were identified whose only concern for the donor was to avoid transgressing the law or being charged with wrongdoing. In his memoirs, Murray recalls that those who attended the International Conference on Human Kidney Transplants in 1963 were "mostly young, aggressive, and ambitious doctors" that eagerly wanted to move forward "unfettered whatever the cost" [59, p. 118]. He even remembers certain doctors saying, "I'm not going to wait for the medical examiner to declare the patient dead; I'm just going to take the organ" [59, p. 120]. Taking on the role of "a mother hen," Murray urged a "cautious optimism" that would result in "slow and steady progress"- the "entrepreneurial zeal for rapid progress" of the young attendants had to be reined in so that their experimental practices would not fall into disrepute [59, p. 118-119]. Perhaps, then, the early transplanters were merely being 'prudential but not moral' with the ethics of their discipline.

Worries about breaking the law do not fully explain the early transplant community's commitment to the DDR, however. There still remains the fact that no one lobbied for a change in homicide law, or at least an exception to it, something that should have been a live option if medical pragmatism ruled the day. Norman Fost is correct when he says, "If immunity was what 
was sought, or assurance that there would be no liability for discontinuing life support or removing organs from a brain-dead patient, there were and are ways of achieving immunity from liability" [60, p. 722]. Statutes could have been rewritten to avoid violating the law, or new statutes could have been created to grant immunity to physicians who operate on brain-dead patients. What explains the community's reluctance to lobby for these changes is that many transplanters were concerned with upholding the time-honored norm against medical killing, which, as they saw it, flowed from a general respect for the value of human life even in its diminished state. They recognized that homicide law as well as the recent formulations of the Nuremberg Code and Declaration of Helsinki was based on something more fundamental, namely, the intrinsic worth of the human being. This is the third and final reason that a change in the definition of death was preferred over a change in the law.

\section{The intrinsic worth of the human being}

The contribution of Swedish urologist Gustav Giertz to the 1966 Ciba meeting is of particular interest, since he recognizes the conflict between the traditional inviolability-of-human-life doctrine and the expansion of legal killing in the medical context [61]. Commenting on the situation in Sweden after the legalization of abortion in 1963, Giertz saw his country approaching a turning point where the hegemony of Christian belief was yielding to a new uncertainty about the ultimate foundations of morality. Despite the changing times, he observed that "there is one norm, however, to which everyone seems to adhere, namely, the worth of the human being" [61, p. 140]. "The inviolateness of human life," according to Giertz, "is based on the belief that every human life, even the most wretched, has a meaning" [61, p. 140]. This belief maintains its grip not because its countenance is rational in a secular context (indeed, he thinks it is not), but because we fear that without it, "respect for the value of the human being and hence 
democracy is in danger" [61, p. 140]. The acceptance of abortion, which in his view terminates a human life at an early stage and deprives someone of the chance to live a long, beneficial life, lends credence to the morality of euthanasia, which presumably terminates a human life at a late stage and only deprives someone of a short life filled with misery. In either case, Giertz says we are forced to face the questions of "whether we can establish the moment when life ceases to have any human value" and whether we can draw a boundary that permits us to "disregard the obligation to protect life" [61, p. 140]. After sensitively considering all of these points, even under the auspices of voluntary informed consent, Geirtz concludes,

It cannot be considered consistent with good medical ethics to use a moribund person as a donor, for he has no possibility of giving his permission or exercising his freedom of choice. Moreover the procedure is in conflict with the widely accepted rule of medical etiquette that personal integrity must be respected. A person dying is still a person living, and he keeps his elementary human rights up to the moment when life becomes extinct. $[61, \text { p. } 147]^{21}$

Thus, it seems that besides a concern for abiding by laws against homicide, there was a strong commitment to respecting the value and integrity of human life, a commitment that was probably a vestige of the Judeo-Christian value system that still haunts our post-Christian culture today. ${ }^{22}$

\footnotetext{
${ }^{21}$ To be sure, when pressed about whether one could consent by an advanced directive to donate one's organs only if one was in a state of irreversible unconsciousness, Giertz replied, "I think it would be better if we were able to take organs from living persons while they are unconscious, but with their previous permission" (quoted in [41, p. 155]). Later, however, he qualified his claim, saying that he was thinking of the kidneys only, not organs like the heart. These remarks were in reference to a Stockholm case where a brain-damaged patient had a single kidney removed and then was taken off a respirator twenty-four hours later. As stated, his remarks are ambiguous, since they occur in a context about the validity of Alexandre's tests for brain death and whether brain-death is equivalent or not to death. There is no evidence to suggest that Geirtz had "higher-brain death" in mind, as if irreparable damage to one's cerebrum were sufficient for death. In fact, Geirtz is aware of such an idea and deems it to be an unacceptable gerrymandering of death; he says such a view would leave the "biological and medical frame of reference" [61, p. 148]. Thus, it appears that he endorsed something like Morrisey's previously mentioned protocol over Alexandre's brain-death-based protocol because he did not agree with Alexandre that the brain-damaged patient was nothing more than "heart-lung preparations"- a description that originates from the dissection laboratory rather than the hospital bedside [62, p. 149].

${ }^{22}$ Evidence for the view that the law against homicide is an artifact of the belief that life is sacred is found in the legal history outlined in the U.S. Supreme Court case Washington v. Glucksberg (1997), which ruled against the constitutionality of physician-assisted suicide.
} 
This quasi-religiously informed respect for life had another application, which is all but forgotten in the DDR literature today: the total well-being of the patient could not be reduced for a medical purpose that did not in some way benefit the patient. The pedigree of this concern for the total well-being of the donor stretches back to the 1600 s, when surgeons were experimenting with tooth transplantation. In 1685, Charles Allen complained that the use of human teeth from the living entailed ruining the health of the one to restore the health of the other. As he wryly observed, "it is only robbing of Peter to pay Paul" (quoted in [63, p. 47]) This same concern was raised by Joseph Fox in 1803, a time when tooth transplant was losing popularity. He wrote, "this operation involved in it a defect of the moral principle, as one person is injured and disfigured, in order to contribute to the luxury and convenience of another" (quoted in [63, p. 48]). Even as late as 1966, Italian transplanters were limited by a 1940 Civil Code that prohibited the removal of any part of the body that would irrecoverably diminish the health and integrity of the body [45, p. 172]. The recognition of this norm helps explain why both France and Italy, at the time of the Ciba meeting, had banned the removal of a single kidney from a living patient. Not even operations like Murray's transplant between identical twins were legal in those countries, which is why Murray grasped for arguments appealing to the avoidance of "psychic trauma"-which would result from losing a loved one if one were prohibited from donating - to show that the donor's total well-being was not necessarily reduced [64].

Given these ethical commitments, it is only natural that the early transplant community became interested in a more precise definition of death. This is especially evident at the more cautious Ciba meeting, which focused mostly on renal transplants, and the more ambitious Cape Town Symposium, which focused exclusively on heart transplants. Reading through the minutes of both meetings shows that the skepticism of diagnosing death by neurological criteria greatly 
decreased in the time that elapsed between them. It is often claimed by "conservative" and "liberal" critics alike that adoption of the neurological criteria for death outlined by the Harvard Ad Hoc Committee [65] was primarily motivated by a concern for maximizing the supply of potential organ donors [4, 66-69]. While disputes over the motives and methods of Henry Beecher and his colleagues are complex and ongoing [62, 70], everyone acknowledged that, if valid, neurological criteria afforded the perfect opportunity to remove healthy organs at the nearest point after the time of death.

While it may be true that by twenty-first-century standards, a sizable portion of the population is willing to permit vital organ procurement from those who are alive but permanently unconscious [71], we should not forget that these judgments are made with the knowledge that organ transplantation is a medically successful enterprise. Of course, this luxury was not available in the 1950s and '60s, when the first transplants were attempted. We have this knowledge because we came to agree through the efforts of clinicians, lawyers, philosophers, theologians, and legislators that "total brain failure" signifies death [72].

It is unlikely that our progress in transplant science could have advanced as quickly as it did without the ventilator-dependent, brain-dead donor, whose functioning circulatory system kept transplantable organs bathed in oxygenated blood. Nonetheless, the progress of transplantation has had the ironic effect of eroding support for the DDR. I examine the reasons for this decline in support in the next section.

\section{Arguments against the DDR}

Despite the fact that neurological criteria are widely considered suitable for diagnosing death, two arguments against both versions of the DDR emerged from scrutinizing the motivations that the Harvard Ad Hoc Committee [65] gave for adopting neurological criteria in the first place- 
specifically, the justification they offered for removing life support from hopelessly unconscious patients and the opportunity they afforded to retrieve healthy organs from these patients. The first argument goes like this:

1. If it is true that doctors should not cause the death of their patients (i.e. kill them) for any reason, then withdrawing life-sustaining treatment upon patient request is impermissible.

2. But it is not impermissible.

3. Therefore, it is false that doctors should not cause the death of their patients for any reason.

This latest iteration of James Rachels" "bare difference" argument [74, 75] is defended by Miller, Truog, and Daniel Brock [15, See also 23, 25, 76]. While Miller and Truog acknowledge that there is a structural difference between active euthanasia and withdrawing life support insofar as the latter can be grounded in the common law right to bodily integrity and the former cannot $[15$, p. 29-30], they deny that any morally relevant difference in the doctor's action depends on the underlying pathology of the patient or on whether withdrawing life support is an "omission" $[15$, ch. 1] or the death of the patient is a foreseen but unintended side effect of withdrawing life support. Although this argument does not directly rebut the DDR, it undercuts its ethical foundation, that is, the norm against killing patients for any reason. If to withdraw life support is to kill, and doing so is permissible on the grounds of poor quality of life and patient autonomy, then the traditional rationale for the DDR fails $[74,75]$. Not surprisingly, this argument is attractive to those who support voluntary active euthanasia and physician-assisted suicide - it is likewise rejected by those who do not $[15,79]$.

The second brain death-related argument against the DDR can be summarized like this:

1. If it is wrong to kill the donor, then it is impermissible to retrieve vital organs from braindead donors.

2. But it is permissible.

3. Therefore, it is not wrong to kill the donor. 
The soundness of this argument, defended by Truog and many others, obviously depends on the claim that brain-dead donors are not really dead [4, 15, 23, 26, 80-82]. Evidence adduced for this claim is that brain-dead bodies are warm to the touch, regulate temperature, heal wounds, fight infection, expel waste, and in some cases even gestate a fetus. Interestingly, however, the ablest defender of this claim and the scholar cited by every brain death critic, D. Alan Shewmon [8385], does not agree that it is permissible to retrieve organs from brain-dead donors. To do so, in his view, would be to harm the donor. Further, Shewmon believes that the view of harm assumed by the likes of Miller and Truog is inadequate because it is "Cartesian" in character [86, p. 292]. ${ }^{23}$ The reason that so few follow Shewmon on this point is that the shortage in the organ supply is deemed "deplorable" [90, p. 38], and any limitation on organ procurement would be “drastic" [15, p. 146] and "needless' [91, p. 320], signifing a "devotion to symbols ahead of the real interest dying patients have in transplantation" [77, p. 272]. ${ }^{24}$

A similar argument against the DDR emerged for the same reasons from the dispute over the DCD procedures that allow transplant surgery to begin two to five minutes after the time of asystole [19]. In the case of heart transplants, there is an alleged incompatibility between the act of harvesting a healthy heart from a "non-heart-beating donor" and the act of declaring death on the basis of circulatory criteria $[92,93]$. Thus, the argument against the DDR can be summarized like so:

1. If it is wrong to kill the donor, then it is impermissible to retrieve vital organs from nonheart-beating donors.

2. But it is permissible.

\footnotetext{
${ }^{23}$ Robert Veatch likewise rejects the soundness of this argument, though he accepts premise (2), and rejects premise (1), because in his view we can be considered dead only if we irreversibly lose our "higher" brain capacities for conscious experience [87, 88]. Even the famed euthanasia advocate Rachels agrees, since in his view it is appropriate to fix "the time of death at the point at which consciousness is no longer possible" [75, p. 43]. Still others defend the idea that brain death is equivalent to death and that we should comply with the DDR [72, 89].

${ }^{24}$ The idea that there might be a deeper concern about what those symbols signify and whether to have an interest in transplantation is to have an interest in a lethal enterprise is not seriously considered.
} 
3. Therefore, it is not wrong to kill the donor.

The soundness of this argument has been defended by Don Marquis and others on the grounds that irreversibility, which is thought to be a necessary condition for death, is not satisfied $[15,77$, 94, 95]. Although some critics of the argument appeal to higher-brain criteria that render premise (1) false [91], others reject premise (2) and demand that the non-heart-beating protocol be revised, if not rejected $[96,97]$. Yet few of those who believe DCD donors are alive at the time of surgery believe that "a procedure that saves many lives ought to be halted" [94, p. 30]. ${ }^{25}$

These arguments find their persuasiveness in the fact that no substantial change in any of our widely accepted practices is required to accommodate their conclusions. We would only need to change the ethical justification for these practices and implement better guidelines for informed consent. The motivation for doing this would be to circumvent longstanding ethical norms that would render transplant surgery (and withdrawing life support) impermissible. As Dominic Wilkinson and Julian Savulescu say, "The cost of preserving those norms will be the death or ongoing morbidity of many individuals," that is, those in need of a healthy organ, and "this may prompt us to consider whether those principles should be revised or rejected" [99, p.

33]. Similarly, Miller and Truog explain:

Honestly facing the situation of vital organ donation poses a critical ethical choice. In order to honor the dead donor rule we can give up vital organ procurement, with the drastic consequence that many patients whose lives could be saved by organ transplantation will die. Alternatively, we can abandon the dead donor rule and justify vital organ transplantation on different grounds. [100, p. 11]

\footnotetext{
${ }^{25}$ Other critics deny premise (1): Tom Tomlinson [98] and John Robertson [8] think the concept of "irreversibility" can be satisfied if we include the donor's do-not-resuscitate order within its scope, which would make any attempt to revive the donor after asystole impermissible. In this view, the modality of impermissibility is thought to be strong enough to satisfy the "irreversibility" condition even if there is a patient in the next room who is in the same physical condition as the donor but wants to be and is able to be revived. Still, others appeal to higher-brain criteria that render premise (1) false [93].
} 
Hence, critics of the DDR would have us tailor our ethical theories concerning the wrongness of killing to fit our current practices, a pattern of thought that reverses the thinking behind the transplant ethics stemming from the 1960s, in which practice was tailored to fit with ethics.

Answering the details of the critic's arguments is another project, but for now I want to note only that, even if we grant the (controversial) first premise in these argument, they each still beg the question against the historic rationale for the DDR, that is, that we ought not to intend the death of an innocent human being. Critics justify the second premise in each argument with what I call the Disjunctive Theory of the wrongness of killing. According to this theory, it is permissible to kill someone, $\mathrm{S}$, if (1) $\mathrm{S}$ is not (or is only minimally) harmed by death, and (2) $\mathrm{S}$ gives valid consent to be killed by some humane means; it is wrong to kill $\mathrm{S}$ if one or the other of these conditions is unsatisfied. Yet this theory is precisely what is under dispute, so it cannot be used as a premise for an argument showing that the DDR ought to be rejected. A good example of this question-begging tactic is deployed by David Rodríguez-Arias, Maxwell Smith, and Neil Lazer in their defense of lethal transplant surgery when they appeal to the moral relevance of informed consent, which to their minds is "the main moral condition justifying voluntary euthanasia" [9, p. 41]. Yet voluntary euthanasia is prohibited for the same reason as lethal transplant surgery according to the rationale for the DDR: the death of an innocent human being should never be intended (and death need not be intended in the case of withdrawing life support [see 101, 102 for details]).

Perhaps, though, the broader strategy of critics is to present a kind of reductio ad absurdum argument against the DDR: if the rationale behind the DDR is true, then transplant surgery is immoral; but it is not immoral, so the rationale is false and the Disjunctive Theory is rendered plausible. However, this argument form is not a reductio; rather, it is a modus tollens. 
There is simply no formal contradiction involved unless one just assumes that lethal transplant surgery or intending death by withdrawing life support is permissible, but that assumption is precisely under dispute. Even critics like Miller and Truog acknowledge that accepting the implication that transplant surgery, as it is currently practiced, ought to be halted is rational, despite the "drastic" outcomes it has [15, p. 146]. No doubt this implication is hard to accept. But the Disjunctive Theory has implications that are hard to accept too, since it allows for the permissibility of lethal medical experimentation. Are advocates of lethal transplant surgery willing to go this far? If not, why not? If the answer is because the benefits from doing so are not likely to follow or are too remote, then we should admit that what motivates the adoption of the Disjunctive Theory is some form of consequentialism that only adheres to the practice of informed consent because of the good outcomes it produces, not because it is the right thing to do.

A commitment to doing the right thing should compel those (like me) who accept the longstanding rationale behind the DDR to call for, or at least be willing to call for, a restraint on our zeal to perpetuate life through organ transplant (e.g. $[103,104])$. That is, we should be willing to bite the bullet and curtail the practices of organ transplantation if the case against our current practices succeeds. ${ }^{26}$ Yet risking this unsavory outcome is not unique to this position, since the majority of donors consistently indicate that they are willing to donate only if they are dead [102]. ${ }^{27}$ If the critics have their way, vital organ transplant will become a deeply divisive

\footnotetext{
${ }^{26}$ It should be noted that I think neither the case for equating withdrawing life support with killing nor the case against declaring death on the basis of total brain failure succeeds at all (see [17, 105-107] for some recent scholarship on these issues). I am currently agnostic about our DCD protocols, however. Another paper for another time.

${ }^{27}$ To be sure, how death is defined is crucial in that there is some support for donating organs when one criterion for "higher-brain" death is satisfied. Be that as it may, James DuBois and Emily Anderson report, "69\% agreed that they would only allow donation after the patient was taken off the ventilator and his or her heart stopped beating, which would require use of a DCD protocol and reduce the number of procurable organs" [108, p. 69].
} 
practice, much like abortion or euthanasia, insofar as it will require physicians to kill in order to achieve their beneficent goals. While Miller and Truog are optimistic that public support for organ donation would not change for the worse if their policy recommendations were implemented, they are willing to risk a net loss in the supply of organs for the sake of being honest with the public $[3,103]$. On this point, at least, they agree that medical practice ought to follow sound moral principles even if they have negative effects on the organ supply, an admirable quality that other critics should imitate.

\section{Conclusion}

As demonstrated in this paper, the DDR is not well defined, and its purpose is sometimes poorly understood. I have argued that its essential moral core is the Don't Kill rule and not the Death Requirement. Historically speaking, the DDR was (and still is) accepted out of an effort to comply with the law against homicide and the traditional medical norm against killing patients for any reason. Respect for the inviolability and dignity of innocent human life, even at its margins, was (and should be) the underlying concern, though it is unclear whether this is still the case. As organ transplantation has become a routine and commonly prescribed treatment, discontent with the rule has arisen alongside a growing dissatisfaction with our currently accepted death criteria as well as an increasing willingness to kill patients on the basis of their autonomous choice or their poor quality of life (or both). What we see today is the opposite of what we saw in the 1960s: the tendency to rethink our laws and ethical theories concerning the wrongness of killing to befit our common medical practices. This should not be the case. Starzl's advice is as timely now as it was then: longstanding ethics recognizing the inviolateness of human life, which require physicians to provide the best care possible to their patients no matter the circumstances, should not be abandoned just because our "advancing technocracy" has made 
great progress. What is needed is less debate about death criteria and (per usual) more consistent, noncircular discussion around the question of what makes killing wrong. ${ }^{28}$ While this question is well worn and much discussed, a broader public consensus is needed on its answer to move the debate forward.

\section{References}

1. Anscombe, G. E. M. 1958. Modern Moral Philosophy. Philosophy 33: 1-19.

2. Chaten, Frank. 2014. The dead donor rule: Effect on the virtuous practice of medicine. Journal of Medical Ethics 40: 496-500.

3. Miller, Franklin G., and Robert D. Truog. 2008. Rethinking the ethics of vital organ donations. Hastings Center Report 38: 38-46.

4. Fost, Norman. 2004. Reconsidering the dead donor rule: Is it important that organ donors be dead? Kennedy Institute of Ethics Journal 14: 249-260.

5. Bernat, James L. 2008. The boundaries of organ donation after circulatory death. New England Journal of Medicine 359: 669-671. doi:10.1056/NEJMp0804161.

6. Coons, Christian, and Noah Levin. 2011. The dead donor rule, voluntary active euthanasia, and capital punishment. Bioethics 25: 236-243.

7. Koppelman, Elysa R. 2003. The dead donor rule and the concept of death: Severing the ties that bind them. American Journal of Bioethics 3: $1-9$.

8. Robertson, John A. 1999. The dead donor rule. The Hastings Center Report: 6-14.

9. Rodríguez-Arias, David, Maxwell J. Smith, and Neil M. Lazar. 2011. Donation after circulatory death: burying the dead donor rule. American Journal of Bioethics 11: 36-43.

10. Bernat, James L. 2013. Life or death for the dead-donor rule? New England Journal of Medicine 369: 1289-1291. doi:10.1056/NEJMp1308078.

11. Fost, Norman. 1999. The unimportance of death. In The definition of death: Contemporary controversies, ed. Stuart J. Youngner, Robert M. Arnold, and Renie Schapiro, 161-178. Baltimore: John Hopkins University Press.

12. Khushf, George. 2010. A matter of respect: A defense of the dead donor rule and of a "whole-brain" criterion for determination of death. Journal of Medicine and Philosophy 35: 330-364. doi:10.1093/jmp/jhq023.

13. Levin, Noah Michael. 2013. The role of death in the moral permissibility of solid organ procurement after cardiac death and its implications. Bowling Green State University.

14. Morrissey, Paul E. 2012. The case for kidney donation before end-of-life care. American Journal of Bioethics 12: 1-8 8p. doi:10.1080/15265161.2012.671886.

15. Miller, Franklin G., and Robert D. Truog. 2012. Death, dying, and organ transplantation: Reconstructing medical ethics at the end of life. Oxford; New York: Oxford University Press.

\footnotetext{
${ }^{28}$ An admirably forthright discussion of the wrongness of killing can be found in the article by Walter Sinnott-
} Armstrong and Miller [110]; for a response to their ideas, see Adam Omelianchuk [111]. 
16. Birch, Samuel C. M. 2013. The dead donor rule: A defense. Journal of Medicine and Philosophy 38: 426-440.

17. Jensen, Steven J. 2011. Killing and letting die. In The Ethics of Organ Transplantation, ed. Steven J. Jensen, 170-194. Washington, D.C.: Catholic University of America Press.

18. Wertin, Thomas M., Mohamed Y. Rady, and Joseph L. Verheijde. 2012. Antemortem donor bilateral nephrectomy: a violation of the patient's best interests standard. The American Journal of Bioethics 12: 17-20. doi:10.1080/15265161.2012.671891.

19. DeVita, Michael A, and James V Snyder. 1993. Development of the University of Pittsburgh Medical Center policy for the care of terminally ill patients who may become organ donors after death following the removal of life support. Kennedy Institute of Ethics Journal: 131.

20. Beauchamp, Tom L., and James F. Childress. 2013. Principles of biomedical ethics. Seventh. New York: Oxford University Press.

21. Cochrane, Thomas I. 2011. Allow the dying to donate: Replace the dead donor rule. In The ethics of organ transplantation, ed. Steven J. Jensen, 135-154. Washington, D.C.: Catholic University of America Press.

22. Chen, Yen-Yuan, and Wen-Je Ko. 2011. Further deliberating burying the dead donor rule in donation after circulatory death. The American Journal of Bioethics 11: 58-59. doi:10.1080/15265161.2011.591211.

23. Collins, Mike. 2010. Reevaluating the dead donor rule. Journal of Medicine and Philosophy 35: $1-26$.

24. Jonsen, Albert R. 2001. Beating up bioethics. Hastings Center Report 31: 40-45. doi: $10.2307 / 3527703$.

25. Miller, Franklin G., Robert D. Truog, and Dan W. Brock. 2010. The dead donor rule: Can it withstand critical scrutiny? Journal of Medicine and Philosophy 35: 299-312. doi:10.1093/jmp/jhq019.

26. Sade, Robert M. 2011. Brain death, cardiac death, and the dead donor rule. Journal of the South Carolina Medical Association (1975) 107: 146-149.

27. Shafer-Landau, Russ. 2015. The fundamentals of ethics. 3 edition. New York: Oxford University Press.

28. Choper, Jesse. 1982. Defining religion in the first amendment. University of Illinois Law Review: 579 .

29. Nussbaum, Martha C. 2012. The new religious intolerance: Overcoming the politics of fear in an anxious age. Cambridge, MA: Harvard University Press.

30. Pellegrino, ED. 2002. Professionalism, profession and the virtues of the good physician. The Mount Sinai journal of medicine, New York 69: 378-384.

31. Starzl, Thomas E. 1992. The puzzle people: Memoirs of a transplant surgeon. Pittsburgh: University of Pittsburgh Press.

32. Ramsey, Paul. 1970. The patient as person: Explorations in medical ethics. New Haven: Yale University Press.

33. Fletcher, Joseph F. 1954. Morals and medicine: The moral problems of the patient's right to know the truth, contraception, artificial insemination, sterilization, euthanasia. Princeton University Press.

34. Williams, Glanville Llewelyn. 1957. The sanctity of life and the criminal law. Knopf.

35. Scribner, BH. 1964. Ethical problems of using artificial organs to sustain human life. Transactions - American Society for Artificial Internal Organs 10: 209-212. 
36. Murray, J. E., J. H. Harrison, and J. P. Merrill. 1955. Renal homotransplantation in identical twins. Surgical Forum 6: 432-436.

37. Barry, John M., and Joseph E. Murray. 2006. The first human renal transplants. The Journal of Urology 176: 888-890. doi:10.1016/j.juro.2006.04.062.

38. Daube, David. 2008. The jottings of david daube: reflections from the 20th century by one of its foremost legal minds. Edited by Calum M. Carmichael. New York: YBK Publishers, Inc.

39. Murray, Joseph E., John P. Merrill, Gustave J. Dammin, J. Hartwell Harrison, Edward B. Hager, and Richard E. Wilson. 1964. Current evaluation of human kidney transplantation. Annals of the New York Academy of Sciences 120: 545-557. doi:10.1111/j.17496632.1964.tb34752.x.

40. Starzl, Thomas E. 1967. Ethical problems in organ transplantation: A clinician's point of view. Annals of Internal Medicine 67: 32-36. doi:10.7326/0003-4819-67-3-32.

41. Wolstenholme, G. E. W., and Maeve O'Connor, ed. 1966. Ethics in medical progress: with special reference to transplantation. London: Churchill.

42. Woodruff, M. F. A. 1966. Transplantation: The clinical problem. In Ethics in medical progress: With special reference to transplantation, ed. G. E. W. Wolstenholme and Maeve O'Connor, 6-23. Boston: Little, Brown.

43. Schreiner, G. E. 1966. Dialysis and transplantation: Ethical problems. In Ethics in medical progress: With special reference to transplantation, ed. G. E. W. Wolstenholme and Maeve O'Connor, 126-133. Boston: Little, Brown.

44. Hamburger, J. 1966. Some general considerations. In Ethics in medical progress: With special reference to transplantation, ed. G. E. W. Wolstenholme and Maeve O'Connor, 134-138. Boston: Little, Brown.

45. Cortesini, R. 1966. Outlines of a legislation on transplantation. In Ethics in medical progress: With special reference to transplantation, ed. G. E. W. Wolstenholme and Maeve O'Connor, 171-181. Boston: Little, Brown.

46. Daube, D. 1966. Transplantation: acceptability of procedures and the required legal sanctions. In Ethics in medical progress: With special reference to transplantation, ed. G. E. W. Wolstenholme and Maeve O'Connor, 188-201. Boston: Little, Brown.

47. Ethical guidelines for organ transplantation. 1968. JAMA 205: 341-342. doi:10.1001/jama.1968.03140320035010.

48. Halley, M, and WF Harvey. 1968. Medical vs legal definitions of death. JAMA 204: 423425. doi:10.1001/jama.1968.03140190005002.

49. Elliot, D.W. 1964. Editorial: When is the moment of death? Medicine, Science and the Law 4: 77-80. doi:10.1177/002580246400400201.

50. Baker, Jeffrey C. 1968. Liability and the heart transplant. Houston Law Review 6: 85.

51. Redefinding death. 1968. Newsweek, May 20.

52. Jentzen, Jeffrey M. 2009. Death investigation in America: Coroners, medical examiners, and the pursuit of medical certainty. Cambridge, Mass: Harvard University Press.

53. Marrison, Benjamin. 1988. Did doctors act to soon in harvest of organs in Pamela James case? The Blade, March 6.

54. Munson, Ronald. 2002. Raising the dead: Organ transplants, ethics, and society. Oxford; New York: Oxford University Press. 
55. Capron, Alexander Morgan, and Leon R. Kass. 1972. Statutory definition of the standards for determining human death: An appraisal and a proposal. University of Pennsylvania Law Review 121: 87.

56. Berman, Emile. 1968. The legal problems of organ transplantation. Villanova Law Review 13: 751.

57. Kutner, Luis. 1969. Due process of human transplants: A proposal. University of Miami Law Review 24: 782.

58. Woodside, Frank C. 1970. Organ transplantation: The doctor's dilemma and the lawyer's responsibility. Ohio State Law Journal 31: 66.

59. Murray, Joseph E. 2001. Surgery of the soul: Reflections on a curious career. Canton, MA: Science History Publications.

60. Fost, Norman. 1983. The new body snatchers: On Scott's The Body as Property. Law \& Social Inquiry 8: 718-732. doi:10.1111/j.1747-4469.1983.tb00890.x.

61. Giertz, G. B. 1966. Ethical problems in medical procedures in Sweden. In Ethics in medical progress: With special reference to transplantation, ed. G. E. W. Wolstenholme and Maeve O'Connor, 139-148. Boston: Little, Brown.

62. Bishop, Jeffrey Paul. 2011. The anticipatory corpse: medicine, power, and the care of the dying. Notre Dame Studies in Medical Ethics. South Bend: University of Notre Dame Press.

63. Hamilton, David. 2012. A history of organ transplantation: ancient legends to modern practice. University of Pittsburgh Press.

64. Murray, Joseph E. 1964. Moral and ethical reflection on human organ transplantation. Linacre Quarterly 31: 54-56.

65. Beecher, Henry K., R. D. Adams, and A. Clifford Barger. 1968. A definition of irreversible coma: Report of the Ad Hoc Committee of the Harvard Medical School to examine the definition of brain death. JAMA 205: 337-340. doi:10.1001/jama.1968.03140320031009.

66. Singer, Peter. 1994. Rethinking life and death: The collapse of our traditional ethics. 2nd ed. New York: St. Martin's Griffin.

67. Giacomini, Mita. 1997. A change of heart and a change of mind? Technology and the redefinition of death in 1968. Social Science \& Medicine 44: 1465-1482. doi:10.1016/S0277-9536(96)00266-3.

68. Oderberg, David S. 2000. Applied ethics: A non-consequentialist approach. Oxford; Malden, Mass: Blackwell Publishers.

69. Koch, Tom. 2012. Thieves of virtue: when bioethics stole medicine. Cambridge, MA: MIT Press.

70. Belkin, Gary. 2014. Death before dying: history, medicine, and brain death. Oxford University Press.

71. Siminoff, Laura A., Christopher Burant, and Stuart J. Youngner. 2004. Death and organ procurement: Public beliefs and attitudes. Social Science \& Medicine 59: 2325-2334. doi:10.1016/j.socscimed.2004.03.029.

72. President's Council on Bioethics. 2008. Controversies in the determination of death: A white paper of the President's Council on Bioethics. Washington, D.C.: President's Council on Bioethics.

73. President's Commission for the Study of Ethical Problems in Medicine and Biomedical and Behavioral Research. 1981. Defining death: A report on the medical, legal and ethical 
issues in the determination of death. Washington, D.C.: The Commission : For sale by the Supt. of Docs., U.S. G.P.O.

74. Rachels, James. 1975. Active and passive euthanasia. New England Journal of Medicine 292: 78-80.

75. Rachels, James. 1986. The end of life: Euthanasia and morality. Studies in Bioethics. Oxford; New York: Oxford University Press.

76. Brock, Dan W. 1992. Voluntary active euthanasia. The Hastings Center Report 22: 10-22. doi: $10.2307 / 3562560$.

77. Arnold, Robert M., and Stuart J. Youngner. 1993. The dead donor rule: should we stretch it, bend it, or abandon it? Kennedy Institute of Ethics Journal 3: 263-278.

78. Glannon, Walter. 2013. The moral insignificance of death in organ donation. Cambridge Quarterly of Healthcare Ethics 22: 192-202. doi:10.1017/S0963180112000564.

79. Smith, Wesley J. 2013. Culture of death: The assault on medical ethics in America. San Francisco: Encounter Books.

80. Truog, Robert D. 1997. Is it time to abandon brain death? Hastings Center Report 27: 2937. doi:10.1002/j.1552-146X.1997.tb00021.x.

81. Riley, Lauren J. 2011. A call to reject the neurological standard in the determination of death and abandon the dead donor rule. Notre Dame Law Review 87: 1749.

82. Sade, Robert M., and Andrea Boan. 2014. The paradox of the dead donor rule: increasing death on the waiting list. The American Journal of Bioethics 14: 21-23. doi:10.1080/15265161.2014.925169.

83. Shewmon, DA. 1997. Recovery from "brain death": a neurologist's apologia. The Linacre quarterly 64: 30-96.

84. Shewmon, D. Alan. 1998. "Brainstem Death," "Brain Death" and Death: A Critical ReEvaluation of the Purported Equivalence. Issues in Law \& Medicine 14: 125.

85. Shewmon, D. Alan. 2001. The brain and somatic integration: insights into the standard biological rationale for equating "brain death" with death. The Journal of Medicine and Philosophy: 457.

86. Shewmon, D. Alan. 2004. The dead donor rule: Lessons from linguistics. Kennedy Institute of Ethics Journal 14: 277-300.

87. Veatch, Robert M. 1975. The whole-brain-oriented concept of death: an outmoded philosophical formulation. Journal of Thanatology 3: 13-30.

88. Veatch, Robert M. 1993. The impending collapse of the whole-brain definition of death. The Hastings Center Report 23: 18-24. doi:10.2307/3562586.

89. Bernat, James L. 1998. A defense of the whole-brain concept of death. The Hastings Center Report 28: 14-23. doi:10.2307/3527567.

90. Jox, Ralf J. 2014. Sketching the alternative to brain death: Dying through organ donation. The American Journal of Bioethics 14: 37-39. doi:10.1080/15265161.2014.925163.

91. Nair-Collins, Michael, and Franklin G. Miller. 2016. Is heart transplantation after circulatory death compatible with the dead donor rule? Journal of Medical Ethics: medethics-2016-103464. doi:10.1136/medethics-2016-103464.

92. Veatch, Robert M. 2008. Donating hearts after cardiac death--reversing the irreversible. The New England Journal Of Medicine 359: 672-673. 18703468. doi:10.1056/NEJMp0805451. 
93. Veatch, Robert M. 2010. Transplanting hearts after death measured by cardiac criteria: The challenge to the dead donor rule. Journal of Medicine and Philosophy 35: 313-329. doi:10.1093/jmp/jhq020.

94. Marquis, Don. 2010. Are DCD donors dead? Hastings Center Report 40: 24-31.

95. Marquis, Don. 2014. Death as a legal fiction. The American Journal of Bioethics 14: 28-29. doi:10.1080/15265161.2014.925160.

96. Joffe, Ari R., Joe Carcillo, Natalie Anton, Allan deCaen, Yong Y. Han, Michael J. Bell, Frank A. Maffei, John Sullivan, James Thomas, and Gonzalo Garcia-Guerra. 2011. Donation after cardiocirculatory death: a call for a moratorium pending full public disclosure and fully informed consent. Philosophy, Ethics, and Humanities in Medicine 6: 1-20. doi:10.1186/1747-5341-6-17.

97. Shewmon, D. Alan. 2010. Constructing the death elephant: a synthetic paradigm shift for the definition, criteria, and tests for death. Journal of Medicine and Philosophy 35: 256298. doi:10.1093/jmp/jhq022.

98. Tomlinson, Tom. 1993. The irreversibility of death: Reply to Cole. Kennedy Institute of Ethics Journal 3: 157-165. doi:10.1353/ken.0.0053.

99. Wilkinson, Dominic, and Julian Savulescu. 2012. Should we allow organ donation euthanasia? Alternatives for maximizing the number and quality of organs for transplantation. Bioethics 26: 32-48. doi:10.1111/j.1467-8519.2010.01811.x.

100. Miller, Franklin G., and Robert D. Truog. 2012. Going all the way: Ethical clarity and ethical progress. The American Journal of Bioethics 12: 10-11. doi:10.1080/15265161.2012.671890.

101. Sulmasy, Daniel P. 1998. Killing and allowing to die: Another look. The Journal of Law, Medicine \& Ethics 26: 55-64. doi:10.1111/j.1748-720X.1998.tb01906.x.

102. Tollefsen, Christopher. 2008. Ten errors regarding end of life issues, and especially artificial nutrition and hydration. In Artificial Nutrition and Hydration, ed. Christopher Tollefsen, 213-226. Philosophy and Medicine 93. Springer Netherlands. doi:10.1007/9781-4020-6207-0_13.

103. Fox, Renée C. (Renée Claire). 1993. "An ignoble form of cannibalism”: reflections on the pittsburgh protocol for procuring organs from non-heart-beating cadavers. Kennedy Institute of Ethics Journal: 231.

104. Fox, Renee C., and Judith P. Swazey. 2013. Spare parts: Organ replacement in American society. Second. New Brunswick: Transaction Publishers.

105. Lee, Patrick. 2016. Total brain death and the integration of the body required of a human being. Journal of Medicine and Philosophy 41: 300-314. doi:10.1093/jmp/jhw005.

106. Condic, Maureen L. 2016. Determination of death: A scientific perspective on biological integration. Journal of Medicine and Philosophy 41: 257-278. doi:10.1093/jmp/jhw004.

107. Moschella, Melissa. 2016. Integrated but not whole? Applying an ontological account of human organismal unity to the brain death debate. Bioethics 30: n/a-n/a.

108. DuBois, James, and Emily Anderson. 2006. Attitudes toward death criteria and organ donation among healthcare personnel and the general public. Progress in Transplantation 16: 65-73. doi:10.7182/prtr.16.1.dv876743k7877rk6.

109. Truog, Robert D., and Franklin G. Miller. 2014. Changing the conversation about brain death. American Journal of Bioethics 14: 9-14.

110. Sinnott-Armstrong, W., and F. G. Miller. 2013. What makes killing wrong? Journal of Medical Ethics 39: 3-7. 
111. Omelianchuk, Adam. 2015. 'Total disability' and the wrongness of killing. Journal of Medical Ethics 41: 661-662. 